\title{
Hyperthermia and its Clinical Application in Cancer Treatment
}

\author{
Asita Elengoe $^{1^{*}}$ and Salehhuddin Hamdan ${ }^{2}$ \\ ${ }^{1 *}$ Department of Biotechnology, Faculty of Science, Lincoln University College, 47301 Petaling Jaya, Selangor, \\ Malaysia \\ ${ }^{2}$ Department of Biosciences and Health Sciences, Faculty of Bioscience and Medical Engineering, Universiti \\ Teknologi Malaysia, 81310 Skudai, Johor, Malaysia
}

Correspondence E-mail: asitaelengoe@yahoo.com*; saleh65@utm.my

\begin{abstract}
The objective of this paper is to describe history of hyperthermia and its clinical applications in cancer treatment. Hyperthermia is a promising approach for cancer therapy which is used to increase the temperature of body tissue by delivering heat obtained from external sources to destroy cancerous cells with minimal or no damaging healthy tissues. There are three main clinical applications of hyperthermia such as local, regional and whole body. Microwaves, radiofrequency, ultrasound, infrared and different kinds of hot sources (hot water, ferromagnetic, nanoparticles) heating approaches are used in some clinical trials. Hyperthermia is administered as an adjuvant to other cancer treatment modalities (multimodal oncological strategies). However, hyperthermia is still facing many challenges in cancer treatment. Some trials continue to use hyperthermia in combination with other novel interstitial technologies such as magnetic fluid hyperthermia and thermolabile liposomes, application of therapeutic monoclonal antibodies under hyperthermic conditions, and hyperthermiainduced gene therapy for the treatment of different cancers which have been discussed. Thus, progress of hyperthermia in clinical applications has already shown some benefits to cancer patients.
\end{abstract}

Keywords: Hyperthermia; Cancer; Clinical application

\section{Introduction}

Worldwide, cancer is a leading cause of death. Hyperthermia is a promising approach to cancer therapy (van der Zee, 2002). It is used to raise the temperature of a region of the body affected by cancer up to $41.5-43^{\circ} \mathrm{C}$ with minimal or no damaging of healthy tissues, using external and internal heating devices. It is applied together with conventional approaches such as radiotherapy and chemotherapy in the treatment of cancer patients. It is proposed that by killing cancer cells and damaging proteins and structures within the cells, hyperthermia may shrink tumors, making the cells more sensitive to radiation therapy (RT) or chemotherapy (American Cancer Society, 2009). The increase of temperature, required can be achieved by various methods. Therapeutic potentials, expenditure of treatment, technical problems and evidence of effectiveness are diverse, based on the different hyperthermia approaches. There are three main clinical applications of hyperthermia such as local, regional and whole body. Results from studies on laboratory animal models and initial human clinical trials have been very promising and suggest that hyperthermia may have a vital role in future cancer treatment. This paper presents an overview of clinical and practical application of hyperthermia. 


\section{History}

The application of heat to treat disease dates back to ancient times but took its modern form only in the last 20 years. In India, the clinical use of hyperthermia in the system of traditional medicine (Ayurveda) applied around 3000 years ago. It formed part of a clinical protocol developed called "Panchakarma" that was used in curative and preventive medicine. The first recorded uses of localized hyperthermia for cancer treatment appeared in the writings of Ramajama (2,000 B.C.)

\section{Combination of hyperthermia and radiotherapy}

Hyperthermia is considered to be one of the most potent radio-sensitizers (Lindner and Issels, 2011). lonizing radiation generates free oxygen radicals which will attack the DNA of tumour cells. This is the primary mechanism of radiotherapy. In spite of the cancer cells low in oxygen and $\mathrm{pH}$ range or in S-phase, are relatively radio-resistant (Jones et al., 2005). This is where hyperthermia may need as a supplementary for radiation therapy. Table 1 shows combination of hyperthermia and radiotherapy.

Table 1: Combination of hyperthermia and radiotherapy treatment in different types of cancer patients

\begin{tabular}{lllllc}
\hline Author & Year & Modality & Tumor entity & Treatment & Response \\
\hline Algan & 2000 & Local & Prostate & Radiation & Yes \\
Van der Zee & 2000 & Regional & Cervix, rectum, Bladder, pelvic & Radiation & Yes \\
Harima & 2001 & Regional & Cervix & Radiation & Yes \\
Jordan & 2001 & Interstitial & Prostate & Radiation & Yes \\
Jones & 2005 & Local & Superficial lesions & Radiation & Yes \\
Vasanthan & 2005 & Regional & Cervix & Radiation & No \\
Mitsumori & 2007 & Local & Non-small cell lung cancer & Radiation & No \\
Matula & 2007 & Local & Prostate & Radiation & Yes \\
Aktas & 2007 & Local & Vaginal & Radiation & Yes \\
van der Zee & 2008 & Local & Vaginal & Radiation & Yes \\
Hulshof & 2010 & Regional & Esophagus & Radiation & Yes \\
Huilgol & 2010 & Intra-cavitary & Head \& neck & Radiation & Yes \\
Hua & 2011 & Local & Head \& neck & Radiation & Yes \\
\hline
\end{tabular}

\section{Combination of hyperthermia and chemotherapy}

Heat and drugs have been shown to interact synergistically in experiments and clinical. This proved that heat enhances the cell killing through direct thermal toxicity and shows thermal enhancement of drug efficacy (Issels,
2008). This is due to heat that can alter tumour cell membrane permeability for the penetration of chemotherapeutic drugs into tissues and absorption by the tumour. Table 2 shows clinical trials of hyperthermia in combination with chemotherapy that have been done in cancer patients.

Table 2: Combination of hyperthermia and chemotherapy treatment in different types of cancer patients

\begin{tabular}{llllll}
\hline Author & Year & Modality & Tumor entity & Treatment & $\begin{array}{l}\text { Respo } \\
\text { nse }\end{array}$ \\
\hline Wessalowski & 2003 & Regional & Soft tissue sarcoma & Chemotherapy & Yes \\
Richel & 2004 & Whole body & Cervix & Chemotherapy & Yes \\
Issels & 2010 & Regional & Soft tissue sarcoma & Chemotherapy & Yes \\
Shen & 2011 & Regional & Non-small cell lung cancer & Chemotherapy & Yes \\
\hline
\end{tabular}




\section{Combination of hyperthermia and surgery}

Hyperthermic intraperitoneal chemotherapy (HIPEC) is a heated chemotherapy approach that is delivered directly to the abdomen during surgery. It is a very concentrated chemotherapy treatment for cancer patients. It is not like systemic chemotherapy delivery because systemic chemotherapy circulates throughout the body. However, HIPEC delivers chemo-drugs directly to cancer cells in the abdomen. This permits for higher doses of chemotherapy treatment. Hyperthermia enhances the absorption of chemotherapy drugs by tumors and kills the microscopic cancer cells that found in the abdomen after surgery. Randomized trials on hyperthermic intraperitoneal chemotherapy (HIPEC) shown in Table 3.

Table 3: Combination of hyperthermia and surgery treatment in different types of cancer patients

\begin{tabular}{llllll}
\hline Author & Year & Modality & Tumor entity & Treatment & Response \\
\hline Scaringi & 2008 & Adjuvant HIPEC & Gastric & Surgery & Yes \\
Spiliotis & 2008 & Adjuvant HIPEC & Peritoneal & Surgery & Yes \\
Elias & 2008 & Adjuvant HIPEC & Pseudomyxoma peritoneal & Surgery & Yes \\
Di Giorgio & 2008 & Adjuvant HIPEC & Ovarian & Surgery & Yes \\
Verwaal & 2008 & Adjuvant HIPEC & Peritoneal & Surgery & Yes \\
Kerkar & 2009 & Adjuvant HIPEC & Stomach & Surgery & Yes \\
Helm & 2009 & Adjuvant HIPEC & Ovarian & Surgery & Yes \\
Elias & 2008 & Adjuvant HIPEC & Colon & Surgery & Yes \\
Baratti & 2010 & Adjuvant HIPEC & Peritoneal & Surgery & Yes \\
\hline
\end{tabular}

\section{Current approaches of hyperthermia}

Hyperthermia might be effective in the enhancement of anti-tumor immune responses (Overgaard et al., 2009; Franckena et al., 2009). Researchers found that combination hyperthermia with immunotherapy produced promising results in experiments and clinical aspects. Hyperthermia improves the immune reactivity through production of heat-shock proteins (HSPs), the activation of antigen presenting cells and changes in lymphocyte trafficking (Appenheimer et al., 2005; Skitzki et al., 2009). Tanaka and his group (2005) administered injection of immature dendritic cells intra-tumorally to enhance antitumor effect of hyperthermia using magnetic nanoparticles to treat melanoma.

A new generation of thermosensitive liposomes has been developed as another innovation which reliably enables the liberation of drugs into a heated tissue at predefined temperatures. Current studies describe that those technologies may largely enhance the thermal control of hyperthermia - guided drug -

\section{References}

Aktas, M., de Jong, D., Nuyttens, J.J., van der Zee, J., Wielheesen, D.H., Batman, E., Burger, C.W. \& Ansink, A.C., (2007). Concomitant targeting. Combination hyperthermia and with phase $1 / / I$ trial of ThermoDox ${ }^{\circledR}$ to treat breast cancer patients was demonstrated in 2010.

Eisenberg et al., 2010 investigated the combining effects of NV1066 (a recombinant herpes simplex virus-1 which is designed to specifically infect, replicate in, and lyse cancer cells) and hyperthermia in the treatment of pancreatic cancer in vitro. They concluded that the combination of hyperthermia and viral infection significantly increased killing of cancer cells to approximately $80 \%$ without damaging normal cells.

\section{Conclusion}

Hyperthermia is a very promising approach in cancer treatment. Although basically an old and historic approach for oncology, hyperthermia is not a well-known treatment modality among patients and scientists. On the other hand, hyperthermia is an effective approach for cancer treatment was proven in experiments and clinical studies. It shows significant positive results in clinical responses for cancer patients when used in combination with other treatment methods.

radiotherapy and hyperthermia for primary carcinoma of the vagina: a cohort study. European Journal of Obstetrics \& 


\section{Elengoe \& Hamdan}

Int J Adv Life Sci Res. Volume 1(1)22-27

Gynecology and Reproductive

Biology, 133(1),100-104.

Algan, Ö., Fosmire, H., Hynynen, K., Dalkin, B., Cui, H., Drach, G., Stea, B. \& Cassady, J.R., (2000). External beam radiotherapy and hyperthermia in the treatment of patients with locally advanced prostate carcinoma. Cancer, 89(2), 399-403.

American Cancer Society (ACS), 2009. Hyperthermia. http://www.cancer.org/docroot/ ETO/content/ETO $12 x$ Hyperthermia.asp.

Retrieved on $17^{\text {th }}$ July 2009.

Appenheimer, M. M., Chen, Q., Girard, R.A., Wang, W.C. \& Evans, S.S. (2005). Impact of fever-range thermal stress on lymphocyteendothelial adhesion and lymphocyte trafficking. Immunological investigations, 34(3), 295-323.

Baratti, D., Pennacchioli, E., Kusamura, S., Fiore, M., Balestra, M.R., Colombo, C., Mingrone, E., Alessanrdro, G. and Deraco, M. (2010). Peritoneal sarcomatosis: is there a subset of patients who may benefit from cytoreductive surgery and hyperthermic intraperitoneal chemotherapy?. Annals of Surgical Oncology, 17(12), 3220-3228.

Di Giorgio, A., Naticchioni, E., Biacchi, D., Sibio, S., Accarpio, F., Rocco, M., Tarquini, S., Di Seri, M., Ciardi, A., Montruccoli, D. \& Sammartino, P. (2008). Cytoreductive surgery (peritonectomy procedures) combined with hyperthermic intraperitoneal chemotherapy (HIPEC) in the treatment of diffuse peritoneal carcinomatosis from ovarian cancer. Cancer, 113(2),315-325.

Eisenberg, D.P., Carpenter, S.G., Adusumilli, P.S., Chan, M.K., Hendershott, K.J., Yu, Z. \& Fong, Y. (2010). Hyperthermia potentiates oncolytic herpes viral killing of pancreatic cancer through a heat shock protein pathway. Surgery, 148(2), 325-334.

Elias, D., Honore, C., Ciuchendea, R., Billard, V., Raynard, B., Dico, R.L., Dromain, C., Duvillard, P. \& Goéré, D. (2008). Peritoneal pseudomyxoma: results of a systematic policy of complete cytoreductive surgery and hyperthermic intraperitoneal chemotherapy. British Journal of Surgery, 95(9), 1164-1171.
Franckena, M., Lutgens, L.C., Koper, P.C., Kleynen, C.E., van der Steen-Banasik, E.M., Jobsen, J.J., Leer, J.W., Creutzberg, C.L., Dielwart, M.F., van Norden, Y. \& Canters, R.A. (2009). Radiotherapy and hyperthermia for treatment of primary locally advanced cervix cancer: results in 378 patients. International Journal of Radiation Oncology Biology Physics, 73(1), 242-250.

Harima, Y., Nagata, K., Harima, K., Ostapenko, V.V., Tanaka, Y. \& Sawada, S., (2001). A randomized clinical trial of radiation therapy versus thermoradiotherapy in stage IIIB cervical carcinoma. International Journal of Hyperthermia, 17(2), 97-105.

Helm, C.W., (2009). The role of hyperthermic intraperitoneal chemotherapy (HIPEC) in ovarian cancer. The oncologist, 14(7), pp.683694.

Hua, Y., Ma, S., Fu, Z., Hu, Q., Wang, L.E.I. \& Piao, Y. (2011). Intracavity hyperthermia in nasopharyngeal cancer: a phase III clinical study. International Journal of Hyperthermia, 27(2), 180-186.

Huilgol, N.G., Gupta, S. and Sridhar, C.R. (2010). Hyperthermia with radiation in the treatment of locally advanced head and neck cancer: a report of randomized trial. Journal of Cancer Research and Therapeutics, 6(4), 492.

Hulshof, M.C.C.M., Van Haaren, P.M.A., Zum Vörde Sive Vörding, P.J., Krishnadath, S., Marsman, W.A., Van Berge Henegouwen, M.I., Geijsen, E.D. \& Crezee, J. (2010). Radiotherapy combined with hyperthermia for primary malignant melanomas of the esophagus. Diseases of the Esophagus, 23(8), E42-E47.

Issels, R.D. (2008). Hyperthermia adds to chemotherapy. European Journal of Cancer, 44(17), pp.2546-2554.

Issels, R.D., Lindner, L.H., Verweij, J., Wust, P., Reichardt, P., Schem, B.C., AbdelRahman, S., Daugaard, S., Salat, C., Wendtner, C.M. \& Vujaskovic, Z. (2010). Neoadjuvant chemotherapy alone or with regional hyperthermia for localised high-risk soft-tissue sarcoma: a randomised phase 3 multicentre study. The Lancet Oncology, 11(6), 561-570. 
Jones, E.L., Oleson, J.R., Prosnitz, L.R., Samulski, T.V., Vujaskovic, Z., Yu, D., Sanders, L.L. and Dewhirst, M.W., 2005. Randomized trial of hyperthermia and radiation for superficial tumors. Journal of Clinical Oncology, 23(13), 3079-3085.

Jordan, A., Scholz, R., Maier-Hauff, K., Johannsen, M., Wust, P., Nadobny, J., Schirra, H., Schmidt, H., Deger, S., Loening, S. \& Lanksch, W. (2001). Presentation of a new magnetic field therapy system for the treatment of human solid tumors with magnetic fluid hyperthermia. Journal of Magnetism and Magnetic Materials, 225(1), 118-126.

Kerkar, S.P., Kemp, C.D., Duffy, A., Kammula, U.S., Schrump, D.S., Kwong, K.F., Quezado, M., Goldspiel, B.R., Venkatesan, A., Berger, A. \& Walker, M. (2009). The GYMSSA trial: a prospective randomized trial comparing gastrectomy, metastasectomy plus systemic therapy versus systemic therapy alone. Trials, 10(1), 121.

Lindner, L.H. \& Issels, R.D., 2011. Hyperthermia in soft tissue sarcoma. Current Treatment Options in Oncology, 12(1), 12-20.

Matula, M., Hyspecka, L., Svoboda, M., Vodarek, V., Dagbert, C., Galland, J., Stonawska, Z. and Tuma, L., (2001). Intergranular corrosion of AISI 316L steel. Materials Characterization, 46(2), 203210.

Mitsumori, M., Zhi-Fan, Z., Oliynychenko, P., Park, J.H., Choi, I.B., Tatsuzaki, H., Tanaka, Y. \& Hiraoka, M. (2007). Regional hyperthermia combined with radiotherapy for locally advanced non-small cell lung cancers: a multi-institutional prospective randomized trial of the International Atomic Energy Agency. International Journal of Clinical Oncology, 12(3), 192-198.

Overgaard, J., Gonzalez, D.G., Hulshof, M.C.C.H., Arcangeli, G., Dahl, O., Mella, O. \& Bentzen, S.M. (1996). Hyperthermia as an adjuvant to radiation therapy of recurrent or metastatic malignant melanoma. A multicentre randomized trial by the European Society for Hyperthermic Oncology. International Journal of Hyperthermia, 12(1), 3-20.
Richel, O., Zum Vorde Sive Vording, P.J., Rietbroek, R., (2004). Phase II study of carboplatin and whole body hyperthermia (WBH) in recurrent and metastatic cervical cancer. Gynecology Oncology, 95(3), 680-685.

Scaringi, S., Kianmanesh, R., Sabate, J.M., Facchiano, E., Jouet, P., Coffin, B., Parmentier, G., Hay, J.M., Flamant, Y. \& Msika, S. (2008). Advanced gastric cancer with or without peritoneal carcinomatosis treated with hyperthermic intraperitoneal chemotherapy: a single western center experience. European Journal of Surgical Oncology (EJSO), 34(11), 1246-1252.

Shen, H., Li, X.D., Wu, C.P., Yin, Y.M., Wang, R.S. \& Shu, Y.Q. (2011). The regimen of gemcitabine and cisplatin combined with radio frequency hyperthermia for advanced nonsmall cell lung cancer: a phase II study. International Journal of Hyperthermia, 27(1), 27-32.

Skitzki, J.J., Repasky, E.A. \& Evans, S.S. (2009). Hyperthermia as an immunotherapy strategy for cancer. Current Opinion in Investigational Drugs (London, England: 2000), 10(6), 550.

Spiliotis, J., Tentes, A.A., Vaxevanidou, A. (2008). Cytoreductive surgery and hyperthermic intraperitoneal chemotherapy in the management of peritoneal carcinomatosis. Preliminary results and cost from two centers in Greece. J BUON, 13(2), 205-210.

Tanaka, K., Ito, A., Kobayashi, T., Kawamura, T., Shimada, S., Matsumoto, K., Saida, T. \& Honda, H. (2005). Intratumoral injection of immature dendritic cells enhances antitumor effect of hyperthermia using magnetic nanoparticles. International Journal of Cancer, 116(4), 624-633.

van der Zee, J., 2002. Heating the patient: a promising approach?. Annals of oncology, 13(8), 1173-1184.

van der Zee, J., González, D., van Rhoon, G.C., van Dijk, J.D., van Putten, W.L. \& Hart, A.A. (2000). Comparison of radiotherapy alone with radiotherapy plus hyperthermia in locally advanced pelvic tumours: a prospective, randomised, multicentre trial. The Lancet, 355(9210), 1119-1125. 


\section{Elengoe \& Hamdan}

Int J Adv Life Sci Res. Volume 1(1)22-27

Van der Zee, J., Kleynen, C.E., Nuyttens, J.J. and Ansink, A.C. (2008). Hyperthermia to improve results in vaginal cancer. Radiotherapy and Oncology, 88(2), 286-287.

Vasanthan, A., Mitsumori, M., Park, J.H., ZhiFan, Z., Yu-Bin, Z., Oliynychenko, P., Tatsuzaki, H., Tanaka, Y. \& Hiraoka, M. (2005). Regional hyperthermia combined with radiotherapy for uterine cervical cancers: a multi-institutional prospective randomized trial of the international atomic energy agency. International Journal of Radiation Oncology Biology Physics, 61(1), 145-153.

Verwaal, V.J., van Ruth, S., de Bree, E., van Slooten, G.W., van Tinteren, H., Boot, H. \& Zoetmulder, F.A. (2003). Randomized trial of cytoreduction and hyperthermic intraperitoneal chemotherapy versus systemic chemotherapy and palliative surgery in patients with peritoneal carcinomatosis of colorectal cancer. Journal of Clinical Oncology, 21(20), 3737-3743.

Wessalowski, R., Schneider, D.T., Mils, O., Hannen, M., Calaminus, G., Engelbrecht, V., Pape, H., Willers, R., Engert, J., Harms, D. \& Göbel, U. (2003). An approach for cure: PEIchemotherapy and regional deep hyperthermia in children and adolescents with unresectable malignant tumors. Klinische Pädiatrie, 215(06), 303-309. 